\title{
Torture Born: Representing Pregnancy and Abortion in Contemporary Survival-Horror
}

\author{
Steve Jones
}

Few issues are as divisive as abortion. Contemporary political debate concretizes that rift: abortion is one of the key issues dividing parties and voters in Obama-era US partisan politics, for example. Abortion has been the subject of numerous political campaigns and legislative changes worldwide in the last decade. ${ }^{1}$ While abortion rates continue to decline in the US (Jones and Jerman 2014), legislation against abortion has dramatically increased; Nash et al. (2014) propose that "[m]ore abortion restrictions were enacted in 2011-13 than in the entire previous decade." These immanent political tensions are mirrored in popular culture of the period. Indeed, dramatizations of abortion have increased exponentially since the early 2000s (Sisson and Kimport 2014).

As someone who researches in the area, I have been struck by how many contemporary horror films carry abortion overtones. Pregnant protagonists feature in many contemporary horror films. Given the themes that drive the horror genre, it is unsurprising that pregnancy is contextualized by violence and terror in these movies. These characteristics are, of course, not unique to $21^{\text {st }}$ century horror: Rosemary's Baby (dir. Roman Polanski, 1968), Dead Ringers (dir. David Cronenberg, 1988), and A Nightmare on Elm Street Part 5: The Dream Child (dir. Stephen Hopkins, 1989) are just three of the famous late $20^{\text {th }}$ century movies in which birth is depicted as petrifying. Yet, in proportion to increased emphasis on abortion in contemporary politics, there has been a noticeable upsurge in horror movies that foreground pregnancy and abortion motifs.

This article will explore various ways in which pregnancy is portrayed in contemporary horror films, aiming to offer a historical record of how pregnancy and horror collude in this period. An article of this length cannot hope to be exhaustive; instead, key examples are employed to evidence important trends in the genre's representation of pregnancy. ${ }^{2}$ Although an overview of various contemporary horror subgenres will be very briefly outlined in the second section to provide broader genre-context, this article mainly focuses on survival-horror narratives: films in which protagonists are hunted, imprisoned or tormented for the majority of the run-time. This subgenre often referred to using the pejorative label "torture porn" - dominated the horror genre during the

\footnotetext{
${ }^{1}$ This article is mainly limited to discussing abortion in relation to the US political context. Where European horror films are discussed in detail, they will be accompanied by relevant information regarding abortion laws in those contexts.

${ }^{2}$ In order to demonstrate that the films cited are representative of broader trends, additional films will be named in the footnotes. The films referred to are principally lower budget, independent horror films. Film-makers working outside of the Hollywood studio system typically enjoy greater freedom to explore contentious issues (such as abortion) and often use controversial themes to differentiate their films from the higher-budget horror exhibited in multiplexes. On these distributional issues and controversial subject matter in contemporary horror, see Jones 2013, 170-186.
} 
period under investigation. ${ }^{3}$ When pregnant protagonists feature in survival-horror, the subgenre's contextual foregrounding of victimization, vulnerability, and ethically fraught life-or-death decisionmaking are imbued with abortive connotations. The same themes pervade prolife rhetoric, and so it may appear that survival-horror propagates an anti-abortion stance; in this view, survival-horror films portray innocent people being subjected to "senseless" carnage thereby mirroring the prolife position that a fetus is an innocent life and abortion is tantamount to murder. In balance, however, these scenarios could equally be read as promoting a prochoice ethos. Since survival-horror narratives center on themes of stalking and imprisonment, the antagonists are characterized as sadistic tormentors who routinely and unjustly restrict the captive protagonists' capacities for free decision-making.

These films are ambivalent insofar as they do not directly proffer either a prolife or prochoice agenda. To read these films as allegorizing one or the other would be to over-simplify and overlook the more complex balance that makes these portrayals so interesting. Rather than embodying an absolute prolife or prochoice stance, these films reflect the conflict between the two positions. In political argumentation, abortion is characterized as a polarized issue. Moreover, abortion rhetoric is typically used as a tool to sway voter allegiance for dichotomously opposed parties. The moralistic discussions that ensue from this divisive foundation are notably abstracted. Rhetoricians from both camps dwell on data-sets and metaphysical beliefs. Such discourse refers to women's rights and the rights of the unborn fetus, ${ }^{4}$ but too little attention is paid to the pressure such rhetoric places on individuals who consider terminating a pregnancy. The decision whether or not to have a child has profound implications for the individual since it amounts to deciding on the long-term future direction of one's life. The reality of making such a difficult and emotionally wrenching decision is lost in the conflict between opposing factions.

Indeed, when posed the question "what do you think makes a woman want to have an abortion?" during an interview for Al Jazeera's Fault Lines series (2013), Ohio State Representative Jim Buchy - who is the co-sponsor of a legal campaign to restrict abortion known as the "heartbeat" bill - responded "it's a question I've never even thought about." Buchy's response illustrates a lack of empathic understanding that is characteristic of so much politico-legal campaigning around this issue. Although prochoice proponents advocate individual freedom to choose, actual individuals and their choices are ultimately negated when the debate amounts to a conflict between prolife and prochoice campaigners' antithetical conceptual positions on abortion. Greene Foster et al. $(2013,81)$ acknowledge that "little is known about women's experiences with and reactions to protesters and

\footnotetext{
${ }^{3}$ On torture porn's popularity and its negative connotations, see Jones 2013. The label "torture porn" is avoided here, precisely because it is commonly (mis)used by those who seek to dismiss popular horror rather than engaging with it.

${ }^{4}$ Throughout, "fetus" is used in reference to all periods of gestation.
} 
how protesters affect women's emotional responses to abortion," yet their study only refers to individuals faced with protests outside abortion clinics. The broader emotional impact dichotomous debating has on public understanding of abortion remains under-theorized.

In contrast to the political debates about abortion, survival-horror narratives (as this article will argue) place emphasis on how difficult choice-making is for its lead protagonists. Survival-horror narratives concentrate on specific characters, situations and reactions rather than dealing in abstracted paradigms and principles. Pregnant protagonists are commonly presented as empathic centers in survival-horror movies, and their emotional reactions (fear, horror, distress, relief and so forth) propel these narratives. In this respect pregnancy-themed survival-horror makes a valuable contribution to the abortion debate, acknowledging that individuals matter. These films thus reflect neither a pro- nor anti-abortion position; instead, they reify the abstracted rhetorical melee that disenfranchises individual decision-makers by speaking for their experiences and imbuing personal choices about one's life-path with political significance.

I do not propose that contemporary survival-horror reifies the experience of undergoing an abortion procedure, or the potential emotional after-effects following one's decision to abort. Rather, contemporary survival-horror reflects shortcomings in political discourse via three approaches to narrativizing pregnancy. First, pregnancy is employed for tonal purposes. Numerous films use pregnancy instrumentally, underscoring a protagonist's pregnancy in a bid to augment the horror for those viewers who hold prolife sympathies; viewers who consider fetuses to be persons will view any threat to pregnant individuals as particularly horrific inasmuch as two lives are endangered. Those viewers who do not agree with the premise that the fetus is a person will not be affected in this way. However, the films seem to bank on the former reaction in cases where pregnancy is fleetingly mentioned, insofar as there is no other apparent reason to mention pregnancy; the character's pregnancy does not add to the plot per se. In that sense, such films appear to advance a prolife position. However, this approach also crucially replicates the political flaw of negating the individual by using pregnancy as a means to an end. Second, a number of films reflect the sense that abortion has been framed as a "women's rights" issue in prochoice campaigning. This principle-led approach underlines that abortion is inextricable from a history of patriarchal control over female sexuality. Again, the individual is lost amidst such argumentation. In survival-horror's torturous terrains, pregnant characters frequently face sexual threat, unlike their male counterparts. Thus, such films evoke the same horrific gendered history drawn upon in political debates. However, rather than focusing on what is at stake for "women" in general, these movies encourage viewers to empathize with individual protagonists and their emotional responses to such threats. That is, the individuals are not reduced to a gender category or that history. Third then, 
these films focus on individuals, encouraging the audience to empathize with the protagonist as they make life-or-death choices and struggle to survive. Narrative drama allows audiences to probe some of the complexities that are brushed over in dichotomous partisan political campaigns.

This article does not seek to advance its author's views on abortion, or argue for either the prolife or prochoice positions more broadly. This analysis intends to examine filmic representations of pregnancy to make the case that contemporary survival-horror movies are an important discursive arena in which abortion politics are figuratively dramatized. Survival-horror is commonly dismissed by critics as exploitative cultural trash (Jones 2013, 30-33). This article situates contemporary horror against a specific political context to demonstrate that denigrating these films also means failing to engage with the important contributions they make to public discourse, particularly from an emotional stance.

\section{Abortion in Contemporary Political Debate}

The abortion debate is characterized by two opposing views about "rights." Prochoice campaigners are commonly invested in women's rights, based on the principles of independence and autonomy. Prolife campaigners are broadly concerned with the sanctity of life, or the fetus's rights. Both factions are interested in the extent to which individuals have control over their own reproductive capacities, and restrictions placed upon legal access to abortion.

These broad positions are evident in contemporary political debate. During his Notre Dame address in 2009, President Obama encouraged prolife and prochoice campaigners to enter into productive debate rather than focusing on dichotomous positions. While some balanced argumentation has followed - such as Princeton University's "Conference on Life and Choice" (October 2010) - abortion remains a divisive topic and is subject to violent contestation. Obama's address is just one high-profile instance that represents an increased political interest in abortion over the last decade. Right-wing proponents have leaned heavily on this issue in party-political debate. Dowland $(2009,610)$ observes that abortion has long been an issue that has mobilized the Christian right against leftist liberalism. ${ }^{5}$ Indeed, the partisan politics of abortion continue to haunt Obama in his second term. For example, Obama has stood accused of using abortion to "pack" the appeals court with liberals in an attempt to filibuster the issue after the Texas House of Representatives passed a ban on late-term abortions (Wolf 2013).

The latter is indicative of a further matter. Contestation over abortion rights has manifested in legislative changes, most notably in a recent "spike in antiabortion bills" (Steinmetz 2011, 1). As

\footnotetext{
${ }^{5}$ The association delineated between prolife movements and right-wing conservativism is intended to make a point about discursive politics, rather than advancing the author's moral judgment on this issue.
} 
Boland (2010) and Sedgh et al. (2011) have proposed in their respective studies of abortion laws, these broad trends are not limited to America. Globally, recent abortion legislation has predominantly focused on the legality and morality of abortions beyond the $20^{\text {th }}-24^{\text {th }}$ weeks of pregnancy. These arguments are fraught, even though official statistics indicate that the number of legally-conducted late-term abortions is negligible. In the UK only $2 \%$ of legal abortions occur beyond 20 weeks, and in the US the percentage is even lower (1.3\%) according to recent governmental data-sets (Pazol et al. 2012; Department of Health 2013). In America, these debates were fuelled by the Bush administration's Partial-Birth Abortion Ban Act (passed in 2003) and, after its overturning, the proposed 2005 Unborn Child Pain Awareness Act. In 2008, British parliament similarly debated the validity of fetal pain.

Many researchers have expressed concerns over the rhetorical strategies involved in such campaigning. The notion of fetal pain intertwines legislative proposals with morally contentious, emotive subject matter in a highly problematic way. Abortion legislation's loaded history augments those concerns. Abortion has been most notably implicated in broader struggles regarding women's rights, for instance (Gerber Fried 2013; Steinberg and Russo 2009; Kaczor 2012). This is certainly how Obama has framed the issue; in his statement regarding the $40^{\text {th }}$ anniversary of Roe vs Wade (2013), Obama proclaimed that "women should be able to make their own choices about their bodies and their health care." In these ways, abortion is foremost positioned as a political, figurative, moral, and public matter. The impact abortion has on individual decision-makers is negated in debates over legal access to abortion, human rights, and hypotheses about fetal pain, all of which are less tangible than the emotional turmoil caused by dichotomous, fervent arguments concerning abortion.

Prolife and prochoice arguments emphasize the sanctity of life and of individual rights, respectively. Both are moral arguments, and both are centered on difficult decisions. The labels "prolife" and "prochoice" suggest that the latter contingent is invested in decision-making, while the former is not. Indeed, "prolife" is substituted for "anti-choice" by some prochoice campaigners. ${ }^{6}$ However, anti-abortionists are also interested in choices. Doing the "right" thing (according to a set of standards) involves the possibility of making the "wrong" decisions. Nevertheless, the label "antichoice" is telling: it underscores that the abortion debate is polarized in a totalizing way. Even where not couched in such overt terms, abortion is typically characterized as an oppositional dispute in political discourse. The debates are polarized because they seek to persuade individual voters to take an absolute position on the issue by siding with one party or the other. Indeed, that split has become increasingly pronounced in America where the "middle-ground" position has shrunk drastically since 2000 , rendering the split between pro- and anti- viewpoints ever starker (Benson

\footnotetext{
${ }^{6}$ See, for example, the views expressed at Abortionrights.org.uk (2013).
} 
Gold and Nash 2012). Yet, as de Crespigny et al. (2010) observe, dichotomized positions on abortion present a "misleading picture" of such a complex issue. Williams (2012) too argues that Americans' attitudes towards abortion are significantly less clear-cut than oppositional campaigning suggests.

The impact on specific individuals who make decisions is secondary in political debate. One unfortunate result of conflicting moral argumentation is that these debates complicate and impinge upon the individual's freedom, prior to the issue of abortion itself. By discussing the abstract rights of "women," "humans," hypothetical (as yet unborn) "babies," and by focusing on law and morality as broad sets of principles, the dilemma faced by individuals who decide whether to abort a pregnancy is overlooked. So too are the emotional impacts that polarized, persuasive rhetoric might have on what is already a difficult choice. As a genre that centralizes distress for emotive impact, horror fills a distinct gap in political debate.

\section{Parenthood and Pregnancy in Contemporary Horror: An Overview}

Many of the 1980s' most financially successful horror films focused on teenagers in peril (leading to the expression "teenie-kill movies" [Wood 1986, 195]). In post-millennial horror, there has been a notable increase in violent horror films focused more consistently on protagonists in their 20s and 30s. That shift has resulted in the accentuation of adult themes in the genre, since a different set of concerns and responsibilities are relevant to these older protagonists compared with their younger predecessors. Survival-horror is contextualized by a broader association of parenthood with trepidation in contemporary horror.

Guardianship is depicted as a terrifying responsibility in a number of horror films. For example, films such as The Daisy Chain (dir. Aisling Walsh, 2008) and The Children (dir. Tom Shankland, 2008) portray protagonists' offspring as menacing. In these films, children threaten the lives of anyone in their vicinity, including their parents. Thus, the nurturing parent-child bond is transformed into a perilous relationship. The two movies cited involve very young children. Consequently, they do not terrorize the films' fully mature adult protagonists in the same way that the physically intimidating teenage antagonists of movies such as F (dir. Johannes Roberts, 2010) and Eden Lake (dir. James Watkins, 2008) do. Rather, films such as The Daisy Chain evoke anxiety over guardian-child relationships and parental responsibility itself. Additionally, movies such as The Tortured (dir. Robert Lieberman, 2010), 7 Days (Les 7 Jours Du Talion, dir. Daniel Grou, 2010), and The Horseman (dir. Steven Kastrissios, 2008) all present parental responsibility as an alarming burden. In these films, children are represented as vulnerable; they are abducted and killed. Parents exact revenge for their child's death, but that violence is compensatory, seeking to make amends for having (by their own assessment) botched their duty as guardians; as one avenging parent proclaims in The Tortured, "we 
failed our son ... it was our responsibility to protect him." Films such as Antichrist (dir. Lars Von Trier, 2009) and Hamal_18 (dir. John G. Thomas, 2004) explore the same theme from another angle, depicting guilt-ridden parents who obsess over their child's death. Such portrayals suggest that parents' sole function is to protect their children, and horror arises from their inability to do so. Thus, in such cases, parental responsibility is characterized as an overwhelming burden.

Other films exploit parents' failure to protect their children as a source of horror. For instance, First Born (dir. Isaac Webb, 2007) and Baby Blues (dirs. Lars Jacobson and Amardeep Kalekaaka, 2008) both depict post-partum depression in extremis, culminating in mothers killing their children. These films again give voice to deep-seated fears about "the worst that could happen"; since parenthood entails being responsible for a child's life, infanticide is the ultimate negation of the guardian role. As such, these films render the responsibility to protect a vulnerable entity as a terrifying burden, conflating failure to protect with inadvertent, mortal harm. In these instances, having children is equated with a host of heavy obligations. In various ways, contemporary horror that is focused on adult protagonists submits that the decision to have children is not to be taken lightly.

Elsewhere in the genre, the same decision is subject to another form of horror: pregnancy occurs regardless of the individual's will to become or remain pregnant. In supernatural films such as Fertile Ground (dir. Adam Gierasch, 2011) and Born (dir. Richard Friedman, 2007), demonic spirits impregnate women. ${ }^{7}$ This sexual-reproductive assault diminishes the protagonists' autonomy in the most personal of ways. For example, in The Unborn (dir. David S. Goyer, 2009), Casey is plagued by a dibbuk that seeks to be reborn via males in her bloodline. Those seeking to help Casey thwart the spirit are killed, including her boyfriend Mark and Casey's best-friend Romy. The haunting begins because Casey falls pregnant. The parallel between pregnancy and possession - taking over one's body from within - correlates pregnancy with incursion, imperilment, and force. ${ }^{8}$ Here, the supernatural is used to present pregnancy as horrifying imprisonment, which locks the pregnant protagonist into a host of terrifying events.

The pregnancy-as-entrapment theme is even more marked in survival-horror, where the spike in pregnancy-themed narratives has been most notable. Few survival-horror films pass sustained, explicit commentary on abortion itself. ${ }^{9}$ However, the subgenre notably emphasizes two themes that are central to the abortion debate: (a) jeopardizing lives and a struggle for survival (which tallies with prolife argumentation), and (b) imprisoning protagonists, impinging on their liberty (which is in

\footnotetext{
${ }^{7}$ Others include The Last Exorcism (dir. Daniel Stamm, 2010), Paranormal Activity 2 (dir. Tod Williams, 2010), and Puffball (dir. Nicolas Roeg, 2007).

${ }^{8}$ The attempts to exorcize the dibbuk in the film's finale are a thinly veiled abortion of sorts.

${ }^{9}$ One exception is the overtly anti-abortion themed film The Life Zone (dir. Rod Weber, 2011), which was produced by the prolife organization Justice for All.
} 
concordance with the prochoice stance). Despite this lack of choice, antagonists also routinely coerce protagonists into making ethically unbearable decisions, such as whether to kill a fellow abductee in order to facilitate their own survival (Jones 2013, 114-117). When pregnancy is evoked in this context, these thematic tropes take on abortive overtones.

As a prototypical example of the subgenre, the Saw series provides a representative case for how pregnancy is associated with life-or-death decision-making in contemporary survival-horror. Following his wife's miscarriage, the series' central killer (John) abducts people and forces them to play deadly games. His aim is to impel his victims not to "take life for granted." The games entail making a fundamental decision, which is summated in the series' dialogic refrain, "live or die: make your choice." Given his motivation (the loss of his child-to-be) and the emphasis he places on life-ordeath choices, John's campaign carries unavoidable abortive connotations. His speeches consist of moralistic statements such as "I don't condone murder ... I despise murderers" and "your will is being tested ... grant somebody the gift of life" (Saw III [dir. Darren Lynn Bousman, 2006]), which reveal John's conservative bias. Indeed, the main games in Saw (dir. James Wan, 2004), Saw II (dir. Darren Lynn Bousman, 2005), and Saw VI (dir. Kevin Greutert, 2009) threaten the participants' family unity. John enforces his moralistic politics with violence.

Although John's speeches sound like prolife propaganda, the films do not plainly support that stance. John's "prolife" oration is undercut by his murderous methods; his attitudes towards life and death are hypocritical. It is also inadequate to suggest that the Saw films are unambiguously prochoice-themed texts, since the captives' decisions to self-preserve almost always cause another person to suffer and die. Both John and his victims strike balances between valuing life and taking life. John's games emphasize decision-making, but their imprisonment and coercion rob them of their freedom to choose. The decision process is as simple as "live or die" according to John, yet that stark simplification sweeps over how difficult such decisions are to make in practice and the contextual pressures that impinge on choice-making. Such entrapment is ubiquitous in contemporary survival-horror, since the subgenre's plots revolve around imposing urgent "either/or" choices on captive protagonists. These coercive scenarios reify the divisive pressures that arise out of the prolife versus prochoice debate.

\section{Pregnancy in/as Survival-Horror: Three Narrative Approaches}

Since they do not constitute a unified cabal (see Jones 2013, 41), survival-horror film-makers do not share a single, uniform approach to depicting and situating pregnancy. However, in this section I will identify three notable approaches to depicting pregnancy across the subgenre (with variations therein). Survival-horror trades on placing protagonists in jeopardy. Thus, pregnancy is routinely 
associated with peril in these films. The major differences between films stem not from correlating pregnancy with danger then, but from how pregnancy is positioned within the narrative framework. In order to draw out the implications of representing pregnancy as horror, following is divided into three sections devoted to ways in which pregnancy is utilized as a narratological tool. The three patterns will be illustrated by drawing on indicative filmic examples.

\section{a) Fleeting Allusion: A Means to an End}

The first approach entails briefly indicating that a protagonist is pregnant. In these cases, the narratives are not overtly shaped by pregnancy. In films such as Resurrection County (dir. Matt Zettell, 2008), The Hills Run Red (dir. Dave Parker, 2009) and Madness (dirs. Sonny Laguna, David Liljeblad and Tommy Wiklund, 2010), ${ }^{10}$ the lead female protagonist is revealed to be pregnant, but the theme remains undeveloped. In such cases it is not immediately apparent why the characters' pregnancy should be mentioned at all. Yet, pregnancy has a dramatic function, anchoring the characters' relationships. To illustrate, in Resurrection County one character's pregnancy provides a point of coherence for the group of protagonists during their ordeal. The party consists of pregnant protagonist Lucy, her partner (Tommy), Lucy's brother and his wife, all of whom seek to preserve Lucy's safety over their own as they are hunted by rural murderers. Lucy's demise drives father-tobe Tommy to exact revenge on Lucy's killer (Anthony). In this case, the narratological purpose of Lucy's pregnancy is to shape the male agents' relationships, and inform the audience about their characters. Hence, in contrast to Lucy's peers, antagonist Anthony does not care about her pregnancy. Lucy reveals that she is with-child while pleading for Anthony's compassion. However, Anthony's insensitivity to her pregnancy - illustrated by his response "another bastard to pollute the world?" - is meant to underline his callousness. Pregnancy is a mechanism that aligns audience sympathy with righteous avenger Tommy over heartless murderer Anthony. Lucy is a secondary protagonist; a means to the end of emphasizing broader character relations and motivations.

Another method of negation is to fleetingly mention pregnancy either in the film's opening, or as an afterthought. For example, The Hills Run Red reserves surviving protagonist Serina's pregnancy for the film's unpleasant epilogue in which her criminally insane captor (Alexa) awaits the infant's arrival, so that she can abduct the newborn. Serina's howling screams close the film, accentuating its bleak tone. Rather than being a narratological driving force, Serina's pregnancy is a tool of abuse: it provides Alexa with a reason to prolong Serina's suffering. Madness (dirs. Sonny Laguna, David Liljeblad and Tommy Wiklund, 2010) presents pregnancy in its introduction to similar tonal effect. In

\footnotetext{
${ }^{10}$ Other examples include Detour (Snarveien, dir. Severin Eskeland, 2009), Dead End (dirs. Jean-Baptiste Andrea and Fabrice Canepa, 2003), Storm Warning (dir. Jamie Blanks, 2007), and Break (dir. Matthias Olof Eich, 2009).
} 
This is pre-print version of an article published in Sexuality and Culture. The final publication is available at Springer via http://dx.doi.org/10.1007/s12119-014-9260-3

the opening sequence, a nameless, heavily pregnant woman is imprisoned in the wilderness. She is swiftly removed from the movie: she is stabbed, and her abdomen is stamped on by her tormentor. The incident is not referenced elsewhere in the narrative, and therefore this sequence has no bearing on the film's plot. The blood bursting out from between the victim's legs during this attack is offered mainly for shock-value. In this regard, the film-makers seem to be relying on viewers perceiving pregnant women as belonging to a special category of victims. ${ }^{11}$ Such a stance leans on the same conceptual premise that prolife campaigners evoke; that two lives (the mother's and the fetus') are at stake when a pregnant individual's well-being is threatened. Madness's only instance of pregnancy is employed to demonstrate just how cruel the film's antagonists are, thereby establishing the level of threat they pose to the narrative's protagonists.

As with The Hills Run Red's unresolved epilogue, Madness reserves pregnancy for tonal purposes rather than to drive the narrative or characterization forward. That difference is especially pronounced in Madness because although her pregnancy marks her as a "special victim," the pregnant character could not be less "special" in relation to Madness's plot: she is not given a name or fleshed out as a character. She is not a protagonist, she is merely a victim. This kind of narrative anonymity is rare in contemporary survival-horror, since the subgenre relies on the audience following a small number of protagonists for the film's duration. Unless the audience can empathize with the protagonists, the endangerment and their survival lacks impact, so these films are usually oriented around the protagonists' experiences (see Jones 2013, 73). Subsequently, pregnant victims tend to be fully-fledged characters rather than incidental figures. Yet it is notable that in a number of these cases where pregnancy is fleetingly mentioned - including The Hills Run Red and Resurrection County - the pregnant character is not the film's lead protagonist. The less prominent the pregnant character is in the film's story arc, the more likely it is that (a) they will be killed off; (b) empathic engagement with their situation will be downplayed or even bypassed; and (c) pregnancy will be adopted as a tonal device rather than a narrative driving force.

In these cases where pregnancy is only alluded to then, pregnancy is used as a means to an end; pregnancy provokes the audience to invest in the film's overarching conflicts, relationships, and atmosphere rather than in the pregnant protagonist-qua-individual. That is, fleetingly mentioning pregnancy does not facilitate empathy for the individual pregnant protagonist and/or the fetus. This method pertinently evokes the sense in which a discourse of rights has been used to engage voters

\footnotetext{
${ }^{11}$ This special victim status is literalized in US law via the The Unborn Victims of Violence Act (2004, Public Law 108-212), which refers to the fetus as an additional victim of some crimes perpetrated against pregnant women (see also Maas 2009, 217-219). Although Madness is a Swedish film, it is an English-language movie set in America. In this regard, the film appears to be pitched towards a US or international marketplace rather than a local audience. The representation of pregnancy - which implies that fetal personhood is a controversial matter - certainly seems to be aimed towards an American rather than a Swedish audience given that "Sweden is usually seen as having the most liberal laws on abortion" in Europe, if not the world (de Cruz 2013, 450).
} 
in broader political campaign narratives as a means to an end (party affiliation). That approach which negates the pregnant individual-qua-individual - is replicated in survival-horror's parallel allusions to pregnancy as a means of advancing the lead protagonists' stories or shaping tone. Since that tone is overtly horrific, such films draw attention to how horrific it is that pregnancy is exploited as a rhetorical tool.

\section{b) Pregnancy/Sexual Maturity as Vulnerability}

A second approach places emphasis on the pregnant lead protagonist's vulnerability as they seek to endure survival-horror's perilous scenarios. Endurance may signify remarkable strength inasmuch as the expectant mother protects not only herself but also her as-yet-unrealized offspring. That doublevictory could be perceived as a marker of power because, compared to a non-pregnant counterpart, the pregnant protagonist has twice as much to lose. Such a reading hinges on the belief that two lives are at stake (mother and fetus) rather than one.

One problem with this pregnancy-as-vulnerability model is its gender exclusivity. Pregnancythemed survival-horror thus risks propagating stereotypical assumptions that women are generally and essentially more vulnerable than men, because lead females are frequently portrayed as being physically susceptible in a way that men cannot be. That disparity is exacerbated where pregnancy is coupled with distinctly gendered sexual vulnerability. ${ }^{12}$ In The Wreck (dir. James K. Jones, 2008), for example, Julia's pregnancy is characterized as vulnerability from the outset. Her husband Frank's initial conversations with his father and a work colleague revolve around Julia's health, and the car crash that entraps the couple results from Frank attending to Julia's uteral discomfort. The association between pregnancy and imperilment is concretized by Julia's reasoning: "I feel like we're being punished. I just wanted to have a baby ... a family." The second sentence implies that Julia sees pregnancy as causally intertwined with their fate. After several days trapped in their vehicle, Julia's water breaks, and Frank's brother (Chuck) arrives on the scene. It is revealed that Chuck previously raped Julia, and Chuck then coerces Julia into performing oral sex on him in exchange for rescuing them. Sexual violence is thus inextricable from vulnerability in a narrative context that also establishes pregnancy as physical weakness. Dark Corners (dir. Ray Gower, 2006) takes that logic a step further. Lead protagonist Susan becomes pregnant following IVF treatment, then miscarries two of her three "viable embryos." The miscarriages manifest in the narrative as vivid nightmares, in which a dream-version of Susan (called Karen) is raped and subsequently suffers forced abortion. In the narrative's climax, Susan is killed, meaning her final embryo is also terminated. The film melds

\footnotetext{
${ }^{12}$ An interesting exception is Resurrection County, in which Tommy is almost raped. However, Tommy is rescued before rape can occur. In contrast, his pregnant fiancée, Lucy, is subjected to rape.
} 
homicide, rape, pregnancy, miscarriage and abortion into one horrific amalgam. Sexual violence is not only exclusively aimed at women in Dark Corners, but it is also inseparable from Susan's own vulnerability, and from the death of the embryos she carries.

Such associations connote that pregnancy itself is an exclusive form of sexual vulnerability since pregnancy most commonly results from intercourse. Following that logic, a number of narratives depict women being abducted precisely because they are able to reproduce. In The Hills Have Eyes 2 (dir. Martin Weisz, 2007), ${ }^{13}$ Missy is imprisoned and raped by desert-dwelling cannibals, for example. Missy's enslavement is underscored by the film's horrific opening images, which portray a woman bound to a bed, giving birth. The nameless woman is bludgeoned to death when, moments after birth, her baby dies. The cannibals reduce the woman to her uteral functionality: she cannot produce living infants, therefore she is deemed worthless, and so she is terminated. Since any other fertile woman could be susceptible to the same fate in this narrative, that reduction is representative of the villains' derogatory attitudes towards women generally.

Although Timber Falls (dir. Tony Giglio, 2007) seems less exclusively gendered than some of its counterparts inasmuch as a couple (Michael and Sheryl) are kidnapped by rural dwellers and are forced to procreate, only Sheryl is represented as sexually vulnerable. During her incarceration, Sheryl narrowly escapes being raped by one of the rural-dwellers (Deacon). That sexual horror is foreshadowed long before the couple are enslaved. Early in the film, a local male (Darryl) declares that he wants to "cut [Sheryl's] eyeballs out and skullfuck her." Exclusively gendered sexual threat is established, and then consolidated by the reproduction-motivated imprisonment that follows. The narrative trajectory ultimately links Sheryl's sexual vulnerability to her fertility.

The theme evokes a history of female oppression, reifying various notions that have been employed when politically subjugating women: that women are physically and sexually weaker than men; that pregnancy is indicative of fundamental, physiological differences between men and women. That is not to suggest that the narratives themselves are misogynistic simply because they connect pregnancy and sexual vulnerability. The horror genre thrives on terror, and so it is unsurprising that where pregnancy is evoked, it is associated with distress. In the survival-horror films such as The Wreck and Dark Corners, pregnant females are presented as the narrative's empathic core. Their situations are portrayed as plights, and the audience is encouraged to fear for and with the protagonists. Without threat and vulnerability, the protagonist's predicament would be less emotively engaging for the audience. Thus, where these films evoke a horrific history of gendered violence and oppression, the narratives nevertheless focus on individual protagonists and

\footnotetext{
${ }^{13}$ Other examples include Dying Breed (dir. Jody Dwyer, 2008), The Embodiment of Evil (dir. Jose Mojica Marins, 2008), Alive or Dead (dir. Stephen Goetsch, 2008), The Clinic (dir. James Rabbitts, 2010), and Primal (dir. Josh Reed, 2010).
} 
This is pre-print version of an article published in Sexuality and Culture. The final publication is available at Springer via http://dx.doi.org/10.1007/s12119-014-9260-3

their emotional responses. Such engagement contrasts with political rhetoric in which individuals are commonly subsumed into a gender category ("women") and their experiences are assimilated into a historical narrative, becoming evidence of continuing gender bias.

\section{c) Foregrounding the Pregnant Lead Protagonist}

A third approach is to foreground pregnancy, focusing on a pregnant lead protagonist for the majority of the film's run-time, and marking her pregnancy as a key character attribute. Frontier(s) (dir. Xavier Gens, 2007) and Inside (a L'interieur, dirs. Alexandre Bustillo and Julien Maury, 2007) both opt for this strategy. ${ }^{14}$ Frontier(s) and Inside open with images of fetuses in utero: Frontier(s) offers an ultrasound image, while Inside's CGI fetus is reminiscent of 3D-ultrasound imagery. ${ }^{15} \mathrm{In}$ addition, the mothers talk about or to their fetus in these opening moments, highlighting the fetus as a focal point.

As Cerulo $(1998,40-43)$ observes, point-of-entry into a text significantly shapes how subsequent violent depictions are interpreted. Where pregnancy is foregrounded in the opening shots, that theme resounds in the ensuing narrative. Inside's narrative is overtly driven by pregnancy for example, being concerned with a mysterious antagonist's attempts to physically extract heavily pregnant lead protagonist Sarah's fetus from her body. The ensuing horror is explicitly focused on Sarah's pregnancy. The pregnancy theme equally resonates throughout Frontier(s), even though lead protagonist Yasmine is in the early stages of pregnancy (and so is not "showing"). Yasmine's opening address to the viewer amalgamates her identity with her fertility: “[m]y name's Yasmine. I'm three months pregnant." This introduction is the foundation for her character and underpins the narrative as a whole. Yasmine is always-already understood as a pregnant character. Unlike her peers (who are slaughtered), Yasmine is detained, and then she is only kept alive because she is pregnant. Thus in both Inside and Frontier(s), the protagonists' attempts to escape their oppressors constitutes the story. Moreover, pregnancy is inextricable from the protagonists' imperilment.

\footnotetext{
${ }^{14}$ Both Inside and Frontier(s) are French movies, and abortion has particular connotations in that national context. Between 1975 and 2014, abortion laws in France were much more restrictive than in the US. Prior to the 2014 reform on abortion law, abortion was only permitted in the first ten weeks of gestation if the pregnant individual was in distress, and only beyond that point if two physicians agreed that the pregnancy endangered the lives of either the fetus or the pregnant individual (on abortion trends and laws in France, see de Cruz 2013, 438; Rossier et al. 2009). Although the 2014 reform legalized abortion on request up until the twelfth week of gestation, that cut-off is far lower than in the US and UK. It is also notable that France's "principled opposition to abortion and pragmatic acceptance of it" is not characterized by the same "divisive politics" found in US political debate on the issue; rather the debates center on "human dignity" and concerns related to Nazi eugenics (Banchoff 2011, 15). Although I do not have space to unpick these cultural differences here, the connotations of Nazism are evoked in Frontier(s)'s right-wing government and neo-Nazi family. However, such cultural specificities do not impact upon the analytical points made regarding the narrative positioning of pregnant women in these films.

${ }^{15}$ On the relationship between ultrasound imagery and the abortion debates, see Gatter et al. 2014; Palmer 2009.
} 
Centralizing pregnancy in this way has a profound effect on the films' narrative arcs. By centralizing the pregnant protagonists' imperilment, the films evoke birth and death as potential outcomes. Inside and Frontier(s) create tension by shifting between these outcomes, exploiting the audience's desire to see the protagonist survive and apprehension that they may not. Both films sustain uncertainty to amplify the horror. Indeed, neither film concludes these arcs by closing with birth as a celebration of life, or death for both mother and child. In Inside, Sarah dies. Although her baby is born, it is nursed by Sarah's stalker. Birth extends the narrative's established terror: the stalker continues to threaten the baby's welfare. Similarly, although Yasmine escapes the neo-Nazi family who imprison her in Frontier(s), she is captured by the fascist government from whom she fled in the film's opening. Frontier(s) does not end in death, but Yasmine's escape is also not cause for celebration. Neither film offers resolution, because the outcomes are never certain. The narratives focus on protagonists' struggles. Pregnancy is a device that underscores how horrific their circumstances are by offering a powerfully intuitive narrative of hope that is continually thwarted.

In contrast to films in which (a) secondary characters are pregnant, and (b) their pregnancy is mentioned only in passing, heavily pregnant lead protagonists are not rendered as a means to an end, even if they die. It is not the case that pregnant lead protagonists are depicted as essentially more vulnerable than their male counterparts. Late-term pregnancy is certainly a physical hindrance in survival-horror's environs where being agile helps protagonists to evade their pursuers, but it is notable that in both The Wreck and Inside the heavily pregnant leads out-last the texts' other protagonists. Since survival-horror depicts characters who seek to endure perilous scenarios, the genre-context underscores the pregnant protagonist's distress: that distress facilitates the audience's emotional engagement with the protagonist's situation. ${ }^{16}$ In films such as Inside and Frontier(s) where pregnancy is centralized from the outset, the lead characters are presented as individuals who are pregnant, rather than "pregnancy embodied."

\section{Surviving Political Pressure: Horror, Emotion and Abortion}

In sum then, the above examples contextualize pregnancy in a number of ways, the implications of which vary depending on at what point pregnancy is revealed, the pregnant protagonist's position in the narrative, the amount of focus pregnancy receives, and whether the motif is adopted for thematic, tonal, narrative, or character development. Cumulatively, these approaches to pregnancy expose how horrific abortion discourse is as a rhetorical apparatus. These survival-horror films could be understood as either (a) replicating politico-rhetorical negation of individuals by using pregnancy

\footnotetext{
${ }^{16}$ On various other tactics used to facilitate audience engagement with distressed protagonists in contemporary horror, see Jones 2013, 70-80.
} 
as a tonal device - a means to an end - or (b) compensating for that negation by concentrating on the pregnant individual. Both interpretations are plausible depending on which narrative approaches one encounters. Yet when survival-horror narratives centralize pregnant female characters and evoke termination, the films do not usually advance a unilateral prolife or prochoice ethos. Rather, since endurance is the life-blood of survival-horror narratives, emphasis is placed on the pregnant individual's emotional turmoil as they try to endure their captors' coercive regimes. Such coercive pressure does not evoke political pro- or anti-abortion sympathies so much as a concern that those dichotomous political positions place individual decision-makers under unnecessary duress.

To illustrate, Inside probes the extent to which external forces entrap the individual, impinging on the pregnant protagonist's freedom to make meaningful autonomous decisions. Sarah spends much of Inside cowering in her own bathroom after being severely injured by a woman who seeks to abduct Sarah's fetus. Sarah is ensnared by her pregnancy, both in the senses that she is targeted only because she is pregnant, and that Sarah does not necessarily want the baby. Although Sarah is confused when her assailant asserts, "[y]ou don't want that child. I'll take good care of him," Sarah's doubts are evinced via her conflicted attitude towards close relationships prior to the attack. Sarah refers to her pet cat (Sarah's only co-habitor) as a "pain in [her] ass," and rejects her mother's attempts to help, declaring "I'd rather be alone." The fetus is equally characterized as diminishing Sarah's independence. Sarah's attitude towards abortion is never explicitly delineated. Yet, Sarah has carried her fetus for the full-term: she is scheduled for inducement the morning after the attack. It is evident that Sarah was pregnant during the car-crash in which her partner (Mattieu) was killed. Since her attitude suggests that she does not necessarily want to be a mother, it is unclear if she has no choice but to keep the baby because she was past the $10^{\text {th }}$ week of pregnancy at the time of the car crash or whether Sarah considers the fetus to represent a continued connection to Mattieu. If the latter, Sarah's assertion that she would "rather be alone" is untrue. If the former, it may be that Sarah does not want the baby but is against abortion on principle.

Regardless, the aggressor's interruption suddenly forces Sarah to choose whether to protect her fetus or save herself. The result of violent external imposition - a stark, dichotomous "live or die" choice - is confusion. When her water breaks, Sarah looks frantically at her naval protrusion and covers it with a towel, figuratively protecting the fetus. Contrarily, when facing down her attacker, Sarah threatens to stab her own stomach with a long needle, thereby holding the fetus hostage. The needle is thus coded as an abortive instrument. Moments later, after a struggle, Sarah uses the same needle to perform an auto-tracheotomy. The needle that previously connoted infanticide becomes a life-saving device. These negotiations elucidate that Sarah's life is intertwined with her fetus'. The decision-making process is one that has a violent impact on Sarah as much as on her fetus. 
Inside demonstrates that artificial external pressure (embodied by the stalker) leaves Sarah in a hopelessly dualistic position. Sarah cannot sacrifice her own life and continue to protect the fetus. Moreover, if Sarah chooses to sacrifice the fetus, the maniacal stalker has no reason to refrain from killing Sarah. Any decision Sarah makes has little to do with genuine freedom of choice. Inside's gruesome violence reifies the impossible pressures external coercion (from both prolife and prochoice campaigners) place upon those individuals who consider aborting a pregnancy. Inside is indicative of the way pregnancy-themed survival-horror depicts the turmoil that abortion rhetoric inculcates.

Contemporary survival-horror has been roundly dismissed by press critics such as Roselyn Phillips (2011), Lacey Terrell (2009) and Tim Robey (2007) as a subgenre that negates its protagonists and trivializes their suffering. That stance overlooks the ways in which survival-horror films centralize their protagonists' emotional states. Similarly dismissive rhetorical strategies are evident in antiabortion argumentation. Saletan's (2011) interpretation of recent poll-data leads him to conclude that many women requesting second trimester abortions do so because they were initially indecisive ${ }^{17}$ and that women have a moral duty to choose as swiftly as possible whether to abort or not. Although Saletan uses these statistics to argue against late abortion, the same figures reveal how difficult such decisions can be. As Ludlow $(2008,32)$ observes, abortion is frequently characterized as "an 'easy way out' of an unwanted pregnancy" by anti-abortion campaigners. Survival-horror films such as Inside and The Wreck, in contrast, illustrate that pregnancy is embroiled with numerous difficult choices about one's future that are not "easy," even in exceptional circumstances. For example, in The Wreck's climactic sequence, paramedics are told not to conduct an emergency caesarean on Julia because "the infant is secondary." Julia responds by stabbing herself in the neck so that the paramedics will save her baby. Julia has the ability to make a decision here, but choice is divorced from the autonomous power that is typically foregrounded in prochoice argumentation. The Wreck represents the conflict between Julia's future ambitions or continued well-being and the fetus's potential future life (if it is born) as emotionally wrenching. Regardless of outcomes, choice is inextricable from sacrifice and suffering in such films. Ultimately, the individual's plight drives survival-horror narratives.

Horror is apposite as a mode of articulating these themes, since it presents them as horrific. Indeed, the rhetoric of horror is routinely evoked on both sides of the abortion debate. For example, in his 2014 State of the World address, Pope Francis directly referred to abortion as "horrific" (Pullella 2014). As Ludlow $(2008,31)$ notes, abortion is associated with "socially constructed responses" such as distaste and offense. Such linkages mean that "traumatic ... patient narratives"

\footnotetext{
${ }^{17}$ This view has been widely contested; for example, see Greene Foster and Kimport 2013.
} 
are envisaged as "horror stories": sites of "fear." By borrowing from the lexis of horror, such rhetoric reveals the trauma that discursive moral posturing seeks to negate: the conflicts and pressures faced by individuals who decide whether or not to terminate a pregnancy.

The movies discussed in this article each reflect aspects of that otherwise inadequately voiced position. Contemporary pregnancy-themed survival-horror films manifest personal fears and weaknesses via its protagonists' failures. The often distasteful, gory images found in survival-horror also concretize the sense of taboo and discomfort that surrounds abortion (much of which is rooted in a historical discourse of sexual vulnerability). In these ways, horror films fill a gap that Ludlow (2008) identifies in the abortion debates: these movies reify "the things we cannot say" about abortion.

Contemporary horror narratives are thus worthy of scrutiny, since they help the public to work through, emotionally engage with and reflect on such pertinent and politically urgent moral concerns. These films are easy to dismiss as offensive, misogynistic or exploitative by those who refuse to engage with their content in detail. Yet, if these movies are ignored, we risk failing to apprehend the important contributions these texts make to public discourse. Sisson and Kimport (2014) contend that "representations influence public perception of abortion care and may play a role in the production of social myths around abortion, with consequences for women's experience of abortion." Yet, it is also vital to recognize that representations can give voice to feelings and anxieties that stem from socio-political pressures. Horror offers a way into engaging with the abortion issue from an intuitive, emotionally alive stance, rather than treating abortion as a political "means to an end." 
This is pre-print version of an article published in Sexuality and Culture. The final publication is available at Springer via http://dx.doi.org/10.1007/s12119-014-9260-3 This version (C) Steve Jones 2014 .

\section{References}

Abortionrights.org.uk (2013). Report Finds Anti-Abortion Groups Misleading Schoolchildren. Abortion Rights. $\quad$ http://www.abortionrights.org.uk/index.php/media-and-resourcecentre/news/481-report-finds-anti-abortion-groups-misleading-schoolchildren. Accessed 11 February 2013.

Banchoff, T. F. (2011). Embryo Politics: Ethics and Policy in Atlantic Democracies. New York: Cornell University Press.

Benson Gold, R., \& Nash, E. (2012). Troubling Trend: More States Hostile to Abortion Rights as Middle Ground Shrinks. Guttmacher Policy Review, 15(1).

Boland, R. (2010). Second Trimester Abortion Laws Globally: Actuality, Trends and Recommendations. Reproductive Health Matters, 18(36), 67-89.

Cerulo, K. A. (1998). Deciphering Violence: The Cognitive Structure of Right and Wrong. New York: Routledge.

de Crespigny, L. J., Wilkinson, D. J., Douglas, T., Textor, M., \& Savulescu, J. (2010). Australian Attitudes to Early and Late Abortion. MJA, 193(1), 9-12.

de Cruz, P. (2013). Comparative Healthcare Law. New York: Routledge.

Department of Health (2013). Abortion statistics, England and Wales: 2012. UK Government. https://www.gov.uk/government/statistical-data-sets/statistics-on-abortions-carried-out-inengland-and-wales-in-2012. Accessed 11 July 2013.

Dowland, S. (2009). 'Family Values' and the Formation of a Christian Right Agenda. Church History, $78(3), 606-631$.

Gatter, M., Kimport, K., Foster, D. G., Weitz, T., \& Upadhyay, U. (2014). Relationship between Ultrasound Viewing and Proceeding to Abortion. Obstetrics \& Gynecology, 123(1), 81-87.

Gerber Fried, M. (2013). Reproductive Rights Activism in the Post-Roe Era. American Journal of Public Health, 103(1), 10-14.

Greene Foster, D., \& Kimport, K. (2013). Who Seeks Abortions at or After 20 Weeks? Perspectives on Sexual and Reproductive Health, 45(4), 210-218. 
Greene Foster, D., Kimport, K., Gould, H., Roberts, S., \& Weitz, T. (2013). Effect of Abortion Protesters on Women's Emotional Response to Abortion. Contraception, 87(1), 81-87.

Jones, R. K., \& Jerman, J. (2014). Abortion Incidence and Service Availability in the United States, 2011. Perspectives on Sexual and Reproductive Health, 46(1), 1-12.

Jones, S. (2013). Torture Porn: Popular Horror after Saw. London: Palgrave-Macmillan.

Kaczor, C. (2012). The Ethics of Abortion: Women's Rights, Human Life, and the Question of Justice. New York: Taylor and Francis.

Ludlow, J. (2008). The Things We Cannot Say: Witnessing the Traumatization of Abortion in the United States. Women's Studies Quarterly, 36(1/2), 28-41.

Maas, J. (2009). Fetal Homicide: Emerging Statutory and Judicial Regulation of Third-Party Assaults Against the Fetus. In J. L. Mullings, J. W. Marquart, \& D. J. Hartley (Eds.), The Victimization of Children: Emerging Issues (pp. 205-232). New York: Routledge.

Nash, E., Benson Gold, R., Rowan, A., Rathbun, G., \& Vierboom, Y. (2014). Laws Affecting Reproductive Health and Rights: 2013 State Policy Review. Guttmacher Institute.

Obama, B. (2013). Statement by the President on Roe v. Wade Anniversary. The White House. http://www.whitehouse.gov/the-press-office/2013/01/22/statement-president-roe-v-wadeanniversary. Accessed 22 January 2013.

Palmer, J. (2009). Seeing and Knowing: Ultrasound Images in the Contemporary Abortion Debate. Feminist Theory, 10(2), 173-189.

Pazol, K., Creanga, A. A., Zane, S. B., Burley, K. D., \& Jamieson, D. J. (2012). Abortion Surveillance. Centers for Disease Control and Prevention: MMWR, 61(8), 1-44.

Phillips, R. (2011). Some Films Should Not Be Seen. (6 December). The Courier Mail (Australia).

Pullella, P. (2014). Pope Francis Calls Abortion 'Horrific' in 'State of The World' Address. (14 January). Huffington Post.

Robey, T. (2007). It's Not Scary - Just Revolting. (27 June). The Daily Telegraph. 
Rossier, C., Tolemon, L., Prioux, F., \& Grieve, M. (2009). Abortion Trends in France, 1990-2005. Population, 64(3), 443-476.

Saletan, W. (2011). When it comes to Abortion, Why Wait? Spiked. http://www.spikedonline.com/newsite/article/11865\#.U8uz5PISZHQ. Accessed 6 December 2011.

Sedgh, G., Singh, S., Henshaw, S. K., \& Bankole, A. (2011). Legal Abortion Worldwide in 2008: Levels and Recent Trends. International Perspectives on Sexual and Reproductive Health, 37(2), 84-94.

Sisson, G., \& Kimport, K. (2014). Telling Stories about Abortion: Abortion-Related Plots in American Film and Television, 1916-2013. Contraception, 89(5), 413-418.

Steinberg, J. R., \& Russo, N. F. (2009). Evaluating Research on Abortion and Mental Health. Contraception, 80(6), 500-503.

Steinmetz, K. (2011). A Push to Limit Abortion. Time, 177(13), 1.

Terrell, L. (2009). The Brutal and the Banal Become Us. (8 March). The Star-Ledger.

Williams, D. K. (2012). No Happy Medium: The Role of Americans' Ambivalent View of Fetal Rights in Political Conflict over Abortion Legalization. Journal of Policy History, 25(1), 42-61.

Wolf, R. (2013). Obama Judicial Nominee Questioned on Abortion, Religion. (24 July). USA Today. Wood, R. (1986). Hollywood from Vietnam to Reagan. New York: Columbia University Press. 